\title{
EL USO DEL PASADO RECIENTE DEL PNV EN EL CONGRESO DE LOS DIPUTADOS. 1977-2015
}

\author{
Guillermo Gómez Calderón \\ Universidad de Extremadura \\ guillermogcalderon@gmail.com
}

\begin{abstract}
RESUMEN: EI PNV, partido de referencia del nacionalismo vasco, presenta una serie de rasgos distintivos entre los que figura un arraigado uso de interpretaciones históricas. Esta persistente atención a la Historia que forma parte intrínseca de su ideología y de la que se nutre, continuó durante el sistema democrático actual en torno al recuerdo de los traumáticos acontecimientos de la década de los 30, al pasado dictatorial y al proceso de transición a la democracia tras la muerte de Franco. El análisis de las intervenciones parlamentarias de sus diputados en el Congreso de los Diputados muestra que ese recuerdo fue utilizado de forma frecuente pero que no fue uniforme en el tiempo sino que su uso presenta oscilaciones no solo en la frecuencia sino en la intencionalidad.
\end{abstract}

Palabras clave: PNV, II República, Guerra Civil, franquismo, Transición.

\section{THE USE OF THE RECENT PAST OF THE PNV IN THE CONGRESS OF THE DEPUTIES. 1977-2015}

ABSTRACT: The PNV, a benchmark party for Basque nationalism, presents a series of distinctive features, including a deep-rooted use of historical interpretations. This persistent attention to History, which is an intrinsic part of its ideology and the one it draws from, continued during the current democratic system around the memory of the traumatic events of the 1930s, the dictatorial past and the process of transition to democracy, after Franco's death. The analysis of the parliamentary interventions of its deputies in the Congress of Deputies shows that this memory was used frequently but that 
it was not uniform in time but that its use presents oscillations not only in frequency but also in intentionality.

Keywords: PNV, II Republic, Civil War, Francoism, Transition to democracy.

Recibido: 7 de mayo de 2021 Aceptado: 8 de septiembre de 2021

En este artículo se analiza el uso del pasado reciente de la historia de España, -II República, Guerra Civil, franquismo y Transición- por parte del Partido Nacionalista Vasco en el Congreso de los Diputados durante los años 1977 y 2015 a lo largo de las 11 primeras legislaturas, -desde la Legislatura Constituyente hasta a X Legislatura-. Por tanto, se han seleccionado de los Diarios de Sesiones correspondientes a las sesiones plenarias, todas las intervenciones de los diputados pertenecientes al Grupo Parlamentario del PNV en los que se hace un recuerdo del pasado tanto en intervenciones donde el objeto del discurso es ese pasado, como en las que el pasado es utilizado de forma intencionada con fines políticos. Se han obviado las numerosas referencias puntuales y las que son utilizadas sin intencionalidad política, es decir, las que aparecen como meramente informativas en un discurso ajeno al objeto que nos ocupa. La muestra de intervenciones ha sido seleccionada mediante un rastreo informático con 58 palabras clave que abarcan fechas, personajes históricos, conceptos políticos y acontecimientos históricos. Lo que se pretende desde un análisis histórico, es mostrar la intencionalidad política que tuvieron los recuerdos del pasado reciente, en este caso del Partido Nacionalista Vasco en el Congreso de los Diputados.

Cuadro 1. PNV: intervenciones con menciones al pasado reciente (1931-

1979). Fuente: Elaboración propia a partir de los Diarios de Sesiones del

Congreso de los Diputados.

\begin{tabular}{|c|c|c|}
\hline LEGISLATURAS & $\begin{array}{c}\text { N. }{ }^{\circ} \text { DE } \\
\text { INTERVENCIONES }\end{array}$ & $\begin{array}{c}\text { N. }{ }^{\circ} \text { DE } \\
\text { MENCIONES }\end{array}$ \\
\hline L. CONSTITUYENTE (1977-1979) & 5 & 17 \\
\hline I LEGISLATURA (1979-1982) & 5 & 10 \\
\hline II LEGISLATURA (1982-1986) & 3 & 6 \\
\hline III LEGISLATURA (1986-1989) & 5 & 17 \\
\hline IV LEGISLATURA (1989-1993) & 2 & 7 \\
\hline V LEGISLATURA (1993-1996) & 3 & 14 \\
\hline VI LEGISLATURA (1996-2000) & 4 & 42 \\
\hline VII LEGISLATURA (2000-2004) & 12 & 39 \\
\hline VIII LEGISLATURA (2004-2008) & 13 & 14 \\
\hline IX LEGISLATURA (2008-2011) & 2 & $\mathbf{1 7 3}$ \\
\hline X LEGISLATURA (2011-2015) & 4 & \\
\hline TOTAL & $\mathbf{5 8}$ & 2 \\
\hline
\end{tabular}


Es una visión parcial del ámbito parlamentario, una muestra focalizada, pero que se ofrece, así fragmentada, como punta de lanza de una investigación que forma parte de un estudio comparado del uso del pasado reciente de todas las fuerzas políticas representadas en el Congreso de los Diputados a lo largo del periodo democrático, actualmente en proceso de elaboración. En total se analizarán 58 intervenciones donde se trataron 173 cuestiones sobre el pasado reciente de diputados pertenecientes al PNV.

Existe una amplia bibliografía en torno a la memoria y al uso del pasado en España. En este sentido se han publicado trabajos de gran interés para los historiadores desde el ámbito de la sociología, sobre todo los estudios de Paloma Aguilar ${ }^{1}$ y es destacable, asimismo, la contribución de historiadores como Santos Juliá, Josep Fontana, Francisco Espinosa, entre otros ${ }^{2}$. En relación con el estudio del nacionalismo vasco destacan por su interés los trabajos de José Luis de la Granja y Santiago de Pablo y, más recientemente los de Gaizka Fernández y Eider Landaberea ${ }^{3}$ Y ya entre los estudios específicamente centrados en la historia del Partido Nacionalista Vasco, resulta imprescindible acudir a autores como Manuel Montero, Alfredo Crespo, Santiago de Pablo o Ludger Mees ${ }^{4}$.

1. Paloma AGUILAR FERNANDEZ: Políticas de la memoria y memorias de la política, Madrid, Alianza Editorial, 2008; ÍD.: "Aproximaciones teóricas y analíticas al concepto de memoria histórica: la memoria histórica de la guerra civil española (1936-1939)", en Carlos BARROS GUIMERANS (Coord.): Historia a debate: actas del Congreso Internacional "A historia a debate". Celebrado del 7 al 11 de julio de 1993 en Santiago de Compostela, Vol. 2, Santiago, Ed. Historia a Debate, 1995, pp. 129-142; ÍD.: Memoria y olvido de la Guerra Civil Española, Madrid, Alianza Editorial, 1996; e ÍD.: La memoria histórica de la guerra civil española (19361939): un proceso de aprendizaje político, Madrid, Centro de Estudios Avanzados en Ciencias Sociales, 1995.

2. Josep FONTANA: "¿Para qué sirve la memoria histórica?", Clío, 61 (2006), pp. 16-17; Abdón MATEOS LÓPEZ: "La construcción de una conciencia histórica democrática y los medios de comunicación durante la 'Transición'. Notas para su estudio', en Rafael QUIROSACHEYROUZE Y MUÑOZ (ed.): Prensa y Democracia. Los medios de comunicación en la Transición, Madrid, Biblioteca Nueva, 2009, pp. 77-86; Francisco ESPINOSA MAESTRE: Contra el olvido. Historia y memoria de la guerra civil, Barcelona, Crítica, 2006; Alberto REIG TAPIA: La cruzada de 1936. Mito y memoria, Madrid, Alianza Editorial, 2006; Santos JULIÁ (Coord.): Memoria de la guerra y del franquismo, Madrid, Taurus, 2006; e ÍD.: "Echar al olvido. Memoria y amnistía en la transición", Claves de Razón Práctica, 129 (2003), pp. 14-25.

3. José Luis DE LA GRANJA: El nacionalismo vasco: un siglo de historia, Madrid, Tecnos, 2002; e ÍD.: El siglo de Euskadi. El nacionalismo vasco en la España del siglo XX, Madrid, Tecnos, 2003; Santiago DE PABLO: "El nacionalismo vasco ante el estado español (1895-1937)", Studia historica. Historia contemporánea, 18 (2000), pp. 79-93; Eider LANDABEREA ABAD: Los "nosotros" en la Transición: memoria e identidad en las cuatro principales culturas políticas del País Vasco (1975-1980), Madrid, Tecnos, 2016; Gaizka FERNÁNDEZ SOLDEVILLA y María JIMÉNEZ RAMOS (Coords.): 1980. El terrorismo contra la Transición, Madrid, Tecnos, 2020.

4. Manuel MONTERO GARCÍA: "La historia y el nacionalismo. La visión del pasado en el partido nacionalista vasco, 1976-2005", Historia Contemporánea, 30 (2005), pp. 247-276; ÍD.: "El nacionalismo moderado durante la Transición. La conquista de la hegemonía en el 


\section{La recuperación de la democracia. 1977-1982}

Tras las elecciones generales de 1977, ocho diputados del Partido Nacionalista Vasco se sentaron en los escaños del Congreso por primera vez desde las últimas elecciones democráticas de febrero de 1936. Y lo hacían con el fin primordial de restablecer los denominados "derechos históricos vascos" y recuperar el Estatuto de Autonomía y el Concierto Económico Vasco para Guipúzcoa y Vizcaya, -consideradas provincias traidoras al movimiento- derogado por Franco en plena Guerra Civil ${ }^{5}$ pues solo Álava y Navarra conservaron el concierto y vieron premiada su fidelidad al alzamiento. Así lo mencionaba Arzalluz en $1978^{6}$.

EI PNV no participó en el proceso de redacción de la Constitución de 1978, tampoco votó a favor de su aprobación, aun así, manifestaba -en palabras de Xabier Arzalluz en la sesión donde se aprobó el texto constitucionalsu intención de colaborar en la profundización de la democracia como ya hizo en la II República cuando tampoco votaron a favor de su Constitución 7 . El recuerdo de la colaboración y fidelidad del Partido Nacionalista Vasco hacia la II República fue un tema recurrente en su uso del pasado. En 1978 rememoró esa fidelidad a la que creen deberse porque ya desde el gobierno

País Vasco", Cuadernos de Historia Contemporánea, 36 (2014), pp. 331-351; e ÍD.: "La presión terrorista durante la Transición y la formación nacionalista de la autonomía vasca", Historia Actual Online, 55 (2021), pp. 23-36; Alfredo CRESPO ALCAZAR: "Autonomía vs. Independencia en el PNV durante la transición española", en Carlos NAVAJAS ZUBELDÍA e Diego ITURRIAGA BARCO (Eds.): Coetánea. Actas del III Congreso Internacional de Historia de Nuestro Tiempo, Logroño, Universidad de la Rioja, 2012, pp. 285-290; Santiago DE PABLO y Ludger MEES: El péndulo patriótico. Historia del Partido Nacionalista Vasco (1895-2005), Barcelona, Crítica, 2005.

5. "Olvidando muchísimos de los favorecidos por el Concierto esta prodigalidad que les dispensó el Poder público, se alzaron en armas en Guipúzcoa y Vizcaya contra el Movimiento Nacional iniciado el 17 de julio último, correspondiendo así con la traición a aquella generosidad excepcional, sin que los constantes requerimientos realizados en nombre de España para hacerles desistir de su actitud lograsen el efecto pretendido. No es, pues, admisible que subsista ese privilegio sin agravio, para las restantes regiones que, con entusiasmo y sacrificio sin límites, cooperaron desde un principio al triunfo del Ejército, y sin mengua también de aquellas normas de elemental y obligada justicia en que ha de inspirarse el nuevo Estado". Extracto del Decreto Ley de Francisco Franco de 23 de junio de 1937. B.O.E. N. ${ }^{\circ} 247$.

6. "Quisiera mencionar el Decreto de Franco de 1937 que dejó sin efecto el concierto económico de Guipúzcoa y Vizcaya y que en su preámbulo lo motivara por la traición de no haberse sumado estas provincias al Alzamiento", Xabier Arzalluz Antia, en DSCD-1978-036 5/4/78.

7. "Colaboraremos con quienes trabajen en la profundización y asentamiento de la democracia, que es trabajo de todos. Tampoco en el período republicano nuestros Diputados aprobaron aquella Constitución, y ahí está el aval histórico de la fidelidad de un Gobierno vasco de la fidelidad de un partido que, no habiendo votado "sí» a la Constitución republicana, defendió su autonomía, aquella Constitución que la hizo posible y aquel régimen en la guerra y en la posguerra durante tantos años", Xabier Arzalluz Antia, en DSCD-1978-130 31/10/78. 
provisional de la república, éste se manifestó favorable a las aspiraciones de autogobierno de Euskadi y elevó a rango de ley el Concierto Económico Vas$\mathrm{Co}^{8}$. Fue una pretensión que contaba incluso con el apoyo de algunos sectores del conservadurismo parlamentario de la República, como recalcaba el PNV en 1981 al recordar las palabras de Calvo Sotelo, líder de Renovación Española en el congreso republicano ${ }^{9}$.

Es un recuerdo continuado que tuvo la finalidad de dejar atrás la actitud titubeante del PNV al estallar la guerra. En efecto, los militantes del PNV se encontraron en 1936 con la disyuntiva de apoyar una sublevación que contaba con el apoyo de la jerarquía eclesiástica, uno de cuyos principios fue el restablecimiento de la normalidad social que entonces presentaba una deriva anticlerical con acciones violentas contra la Iglesia o, por el contrario, alinearse con el gobierno que les otorgaba el Estatuto de Autonomía. Esa actitud vacilante en los primeros momentos ocasionó la paradoja de que en Álava y en Navarra, las fuerzas nacionalistas, bien se inhibieron, bien apoyaron la sublevación militar, mientras que en el norte optaron por defender el orden republicano ${ }^{10}$. Ante ello, un dirigente del PNV, Iñaki Anasagasti, insistía en resaltar 50 años más tarde el apoyo inequívoco del PNV a la República alejando el fantasma de colaboracionismo de esos sectores nacionalistas ante el avance de las tropas franquistas en el País Vasco ${ }^{11}$.

8. "Hasta la propia República, en una de sus primeras manifestaciones, estableció y elevó a rango de ley los propios conciertos económicos, y aquel primer Gobierno provisional de la República, en el Decreto de 28 de mayo de 1931, proclamó aquel canto a las propias libertades vascas, cuando dijo: "sintiendo la satisfacción de rendir tributo de simpatía al País Vasco, cuya Administración pública es verdaderamente ejemplar...»", José Ángel Cuerda Montoya, en DSCD-1978-133 8/11/78.

9. Jesús María Elorriaga, en DSCD-1981-159 9/4/81 citó estas palabras de Calvo Sotelo: "No por privilegio -lo dije en aquel acto y lo repito ahora-, sino por razones históricas ancladas en lo más antiguo de vuestros principios y vuestras instituciones, disfrutáis especialidades económicas y administrativas que ya quisiera Cataluña en lugar del Estatuto que le ha dado la República. Porque el concierto económico -y el que no lo diga así, conociendo y entendiendo este problema, no es sincero-, el concierto económico vale cien veces más que todo el Estatuto de Cataluña: en esencias de soberanía, en amplitud de concesiones, en conjunto de facultades, en totalidad de franquicias. El concierto económico, yo, si hubiera que optar, lo preferiría para mi querida región gallega mil veces más que el Estatuto de Cataluña", José Calvo Sotelo Diario de Sesiones de la II República N. ${ }^{\circ}$ 273 de 5 de diciembre de 1935.

10. En relación con la postura del PNV ante el golpe de Estado véanse: Santiago de PABLO y Ludger MEES: El péndulo patriótico. Historia del Partido Nacionalista Vasco..., pp. 169-173; Roberto MUÑOZ BOLAÑOS: Guernica. Una nueva historia. Barcelona, Espasa, 2017, pp. 6466 y 76-81 y José Luís de la GRANJA SAINZ: El siglo de Euskadi. El nacionalismo vasco en la España del siglo XX..., pp. 221-227.

11. "Como dijo quien fuera luego nuestro primer lendakari, José Antonio de Aguirre, planteado el problema de la sublevación militar, nuestra posición fue clarísima. Luchando la democracia contra el fascismo, el nacionalismo vasco habría de colocarse, como siempre en su 
También el PNV recordaría de forma reiterada que todavía en 1978, tres años desde la muerte de Franco y superada la dictadura, seguía vigente ese decreto de guerra de Franco que suprimió el Concierto Económico vasco, urgiendo al Gobierno a su pronta restauración, algo que se conseguiría el 9 de abril de 1981 durante la I Legislatura ${ }^{12}$. Antes, por medio de la Ley Orgánica 3/1979, de 18 de diciembre, se estableció el Estatuto de Autonomía para el País Vasco que incluía el restablecimiento de los "derechos históricos vascos". Las relaciones de orden tributario entre el Estado y el País Vasco serían reguladas mediante el sistema foral tradicional de Concierto Económico. Se recuperaba así el autogobierno conseguido en 1936. Fue éste un Estatuto que llegó mucho más tarde que el de Cataluña; anómalo porque se aprobó comenzada ya la Guerra Civil y efímero por quedar sin efecto al poco tiempo de decretarse por la fuerza de las armas, pero que representó un valioso logro para el nacionalismo vasco. Para el PNV supuso la recuperación parcial del autogobierno perdido: "Llegó la República, y el Estatuto de 1936 supuso una feliz recuperación de parte de esa autonomía, de parte de ese autogobierno perdido por el pueblo vasco ${ }^{13 \prime}$. Pero ¿a qué se refiere el diputado José Ángel Cuerda con esa parte de autogobierno perdido? Para responder a esta pregunta, hemos de referirnos a Sabino Arana, fundador del nacionalismo vasco. Para él, en su primera etapa de nacionalismo radical y antiespañol, Euskadi era una nación independiente desde tiempos inmemoriales conquistada por España y que nunca había formado parte de ella. Por ello, los vascos estaban obligados a conseguir por cualquier medio la vuelta a la independencia. Más tarde el pensamiento de Arana evolucionó hacia una postura posibilista, de consecución de mayores cuotas de autogobierno para alcanzar al fin la independencia del País Vasco, por medio de la colaboración con el Estado Español. Si citamos esta evolución ideológica del pensamiento de Sabino Arana es porque en él están impresas las contradicciones que a lo largo de su historia van a definir las luchas internas y los posicionamientos de los partidos nacionalistas vascos, esto es, la oscilación entre una postura moderada de consecución de una autonomía otorgada por el Estado y otra de ruptura para lograr una independencia plena de Euskadi. El PNV, a lo largo de su dilatada historia, mani-

historia se colocó, al lado de la democracia", Iñaki Anasagasti Olabeaga, en DSCD-1986-003 23/7/86.

12. "Esos regímenes económico-administrativos, los conciertos, fueron suprimidos en Vizcaya y Guipúzcoa por un decreto de guerra dictado por el General Franco, después de la ocupación de Bilbao, y cuyos efectos siguen estando vigentes, a pesar de encontrarnos en plena democratización del Estado. Hace muy poco tiempo estas Cortes acordaron conceder la amnistía a todas aquellas personas que hubieran incurrido en delito de intencionalidad política. Hoy se da la paradoja de que unas provincias, partes de un pueblo determinado, siguen siendo objeto de una sanción de guerra sin haberse podido acoger a una amnistía", Pedro María Sodupe Corcuera, en DSCD-1978-112 18/7/78.

13. José Ángel Cuerda Montoya, en DSCD-1978-133 8/11/78. 
fiesta esa pulsión ideológica pendular, que transita entre su independentismo aparentemente teórico y su estatutismo práctico ${ }^{14}$. Para el partido, estas contradicciones supondrán que el Estatuto de 1936 no sería sino un primer paso en la lucha por la independencia de Euskadi ${ }^{15}$. A la altura de 1979 no parecía que la consecución autonómica fuese ese primer paso, sino más bien la culminación de unas pretensiones de recuperación de autogobierno por fin realizadas. La política pendular del PNV respecto a la autodeterminación del País Vasco, una vez conseguido el Estatuto y restablecido el Concierto, se hallaba en estos momentos aparentemente del lado posibilista y colaborativo con el Estado. Imbuido en el espíritu de concordia que parecía presidir las sesiones parlamentarias constituyentes, Xabier Arzalluz declaraba sobre ese periodo:

El que esa ruptura en vez de ser a un tiempo haya ido progresando en forma evolutiva, pacifica, ahorrando al país un gran costo social, aunque demorando, es cierto, la democratización profunda del mismo es mérito de todos los ciudadanos, de las fuerzas políticas y sindicales que, dejando de lado agravios y maximalismos, han sabido tenderse la mano para colaborar en lo fundamental. Esta Cámara, con la enorme variedad de origen e ideología de sus componentes, es fiel reflejo de este esfuerzo, y es mérito también de la Corona y de su Gobierno ${ }^{16}$.

En un hemiciclo formado por antiguos dirigentes franquistas sentados junto con diputados directamente implicados en la contienda y en la lucha antifranquista, las numerosas referencias a la guerra, al exilio y a la dictadura aparecían de forma contenida en el Congreso probablemente por un cierto temor tácito de resucitar viejas querellas que entorpecieran el desarrollo democrático, o dicho de otra forma, prácticamente no se utilizaba el pasado como arma política sino como recuerdo, reivindicación y voluntad de reparación. Así, el PNV mencionaba el papel que desde el exilio realizó el partido: por una parte, recordando su actividad europeísta de acercamiento y colaboración en el proceso de construcción europea y por otra, de entorpecimiento a cualquier intento de la dictadura franquista de aproximación al proyecto europeo ${ }^{17}$.

14. Santiago DE PABLO y Ludger MEES: El péndulo patriótico. Historia del Partido Nacionalista Vasco..., p. 26.

15. Santiago de PABLO, "El nacionalismo vasco ante el estado español (1895-1937)...", pp. 79-93.

16. Xabier Arzalluz Antia, en DSCD-036-1978 5/4/78.

17. "Nosotros -me estoy refiriendo al Partido cuyos parlamentarios represento aquí- hicimos durante el período del anterior régimen todo lo posible para que los intentos de acercamiento a las instituciones europeas a partir de los Gobiernos de Franco no tuvieran un resultado feliz. A partir de nuestra presencia en Europa, en instituciones federalistas europeas, en la Internacional Demócrata-cristiana, aprovechamos -tengo que decirlo, y tal vez hoy se pueda discutir esta política, pero así lo hicimos- nuestras gentes en el exilio para combatir 
En relación con la Guerra Civil, el PNV aludía, respecto a las responsabilidades de la guerra, que la sublevación de una parte del ejército contra la legalidad republicana y con apoyo de Alemania e Italia fue el detonante del inicio de una guerra fratricida que rompió España en dos mitades enfrentadas entre sí. La inacción de los países democráticos europeos ante el conflicto es considerada como parte responsable del triunfo de las tropas franquistas ${ }^{18}$. Y en cuanto a la represión franquista, se ceñía a señalar que supuso el desprecio por la lengua y cultura catalana desde el principio de la dictadura, algo que los vascos también sufrieron $^{19}$.

Con el partido centrado en la gobernabilidad del País Vasco tras el triunfo del PNV en las primeras elecciones al parlamento vasco en 1980; en la presión al Estado para el desarrollo de nuevas competencias autonómicas. -que llevó al PNV a abandonar durante un tiempo las Cortes por temor a la paralización de transferencias y un recorte del Estatuto Vasco- y en la situación de violencia en Euskadi, el PNV, a la altura de 1982, encaraba la tarea política con una postura ambivalente entre el apremio por conseguir y desarrollar competencias autonómicas en colaboración con el Estado y a la vez mantener alto su "estatus abertzale" ante una sociedad vasca que en buena parte mostraba sus simpatías hacia $\mathrm{ETA}^{20}$. Esto tuvo como consecuencia que el partido, por una parte, condenara la violencia en el País Vasco y por otra, que aún no reconociera a la banda su carácter terrorista.

\section{La alternancia que consolidó la democracia. 1982-1996}

En 1982, el PSOE consiguió la mayoría absoluta en las Elecciones Generales, cuatro años después, en las elecciones al Parlamento Vasco de 1986, el PSE logró más escaños, pero no más votos que el PNV. Un pacto de legislatura per-

todo acercamiento que a nuestro entender podía fortalecer la dictadura", Xabier Arzalluz Antia, en DSCD-1979-021 27/6/79.

18. "Los aliados, para no irritar a Hitler y darle pretexto de guerra, fueron cediendo progresivamente. El apoyo de los nazis en 1936 ni siquiera fue contestado en Europa, porque ni Francia ni Inglaterra estaban preparadas para una guerra", Andoni Monforte Arregui, en DSCD-1981-192 28/10/81.

19. "A partir de entonces [1939], el pueblo catalán, como otros pueblos, sufrirá la más dura incomprensión y su lengua y su cultura serán objeto de desprecio y represión", Marcos Vizcaya Retama, en DSCD-049-1979 29/11/79.

20. La coalición Herri Batasuna fundada entre otros por Telesforo Monzón -militante del PNV hasta 1977-, fue la segunda fuerza política más votada en las elecciones con un 16,5\% de los votos. Con su abstencionismo propició la investidura como Lehendakari de Carlos Garaikoetxea y el gobierno monocolor del PNV. El otro gran partido nacionalista de izquierda, Euskadiko Ezquerra y brazo político de ETA pm en ese momento, consiguió un 9,82\%, véase Francisco José LLERA RAMO: "Pluralismo y gobernabilidad en Euskadi, 1980-1994", WP Institut de Ciències Polítiques i Socials, 162 (1999), pp. 1-33. 
mitió a los nacionalistas que José Antonio Ardanza fuera investido lehendakari y Ramón Jáuregui vicelehendakari con seis consejeros cada partido. Este pacto supuso un importante desarrollo de las instituciones autonómicas vascas. También en 1986, Felipe González fue investido de nuevo presidente con los únicos votos del PSOE, el resto de los partidos votó en contra, excepto la minoría vasca, que se abstuvo. Las menciones al pasado del PNV en este periodo de gobiernos socialistas se centraron en destacar los paralelismos y acuerdos puntuales entre ellos y el PSOE a lo largo de sus dilatadas historias, -ambos son los partidos políticos con representación parlamentaria más antiguos por su fecha de fundación-. Así, el PNV señalaba que juntos compartieron gobierno durante la II República bajo las presidencias de Largo Caballero y Negrín, a través del ministro Manuel de Irujo del PNV y que juntos compartieron lucha por conseguir el Estatuto de Autonomía durante la república ${ }^{21}$. De esta manera se enlazaba esa trayectoria histórica común con los acuerdos o pactos de legislatura entre el PNV y el Partido Socialista de Euskadi y la abstención que avaló de alguna manera la investidura de Felipe González en 1986, de ahí la intencionalidad de ese discurso. Este recuerdo de asociación histórica en la II República entre los dos partidos formando parte del mismo gobierno, vuelve a surgir en varias ocasiones a lo largo del tiempo. En 1993, con ocasión de la investidura de Felipe González como presidente del Gobierno por cuarta vez, éste necesitó los votos de CiU y del PNV ya que no obtuvo mayoría absoluta en las elecciones y José Juan González de Txabarri, en 1995 volvía a recordar la participación del PNV en el gobierno socialista de Largo Caballero ${ }^{22}$.

Las menciones del PNV a las consecuencias traumáticas de la Guerra Civil en vidas humanas derivadas de acciones militares y medidas represivas empiezan a emerger en este periodo con mayor frecuencia y son referidas fundamentalmente a lo sucedido en el País Vasco. Los bombardeos de Guernica y Durango y la caída de Bilbao en manos del bando nacional son recordados en

21. "El Partido Nacionalista Vasco - partido que la semana que viene cumplirá noventa y un años- tiene tras sí una antigua experiencia de relación con el Partido Socialista. Desde la barricada, la huelga y la refriega callejera, hasta la lucha por el primer Estatuto de Autonomía conseguido en 1936. Desde la acción del Gobierno central, pues no olvidamos que aquí, hace cincuenta años y en el banco azul, bajo la presidencia socialista de Francisco Largo Caballero, estaba sentado el Ministro nacionalista vasco Manuel de Irujo; desde la guerra y las trincheras; desde un exilio compartido de cuarenta años, pasando por un frente autonómico suscrito con ustedes en 1977, al actual pacto de legislatura, firmado en enero de 1985 entre el Gobierno vasco y el Grupo Parlamentario Socialista de Euskadi", Iñaki Anasagasti Olabeaga, en DSCD1986-003 23/7/86.

22. Como saben SS. SS., el Partido Nacionalista Vasco participó activa y decididamente en estos programas del Gobierno republicano, de aquellos legítimos gobiernos de la República que fueron presididos por Negrín y por Largo Caballero, con su presencia en la persona del ministro de Justicia, don Manuel de Irujo, nacionalista vasco", José Juan González de Txabarri, en DSCD-1995-186 28/11/95. 
diversas ocasiones. Unas veces en relación con la falta de apoyo militar por parte del gobierno republicano ${ }^{23}$, y otras para afianzar la responsabilidad del bombardeo de Guernica de las fuerzas sublevadas mediante la aviación alemana. Un episodio que en su día fue presentado por parte de la propaganda nacional como un acto cuyos responsables fueron los propios defensores republicanos ${ }^{24}$.

El aislamiento internacional de España por su alianza con el fascismo italiano y la Alemania nazi dejó al país fuera de los organismos internacionales que surgen tras la II Guerra mundial, así como del Ilamado "Plan Marshall" de reconstrucción europea tras la guerra. Los acuerdos militares de EE. UU. con España en 1953 y la visita del presidente Eisenhower en 1959, afianzaron el régimen franquista que logró alinearse con las potencias occidentales tras años de aislamiento. El diputado Andoni Monforte, ante la convocatoria del referéndum sobre la permanencia de España en la OTAN, declaró en 1986 que, tras el nacimiento de la OTAN, pensaban que el régimen caería pues la dictadura franquista había sido aliada de Hitler y Mussolini y además que eso supuso dejar fuera al país del Plan Marshall ${ }^{25}$. Con el acercamiento de EE. UU. al régimen franquista, éste dio por cumplida esa recuperación en las relaciones internacionales. Para el PNV, partido que ha querido resaltar su papel internacionalista y europeo durante su acción antifranquista en el exilio, esta vinculación con las potencias occidentales supuso un jarro de agua fría para sus pretensiones de derrotar el régimen de Franco mediante las gestiones de la Junta de Liberación Nacional en San Francisco que consiguió aislarlo en organismos como la ONU. Cabe destacar que el PNV no formó parte de la JEL que agrupaba buena parte de

23. “...se formó el primer Gobierno vasco, que colaboró lealmente, a pesar de las circunstancias, con el Gobierno del Estado. En aquel momento las discrepancias no estaban tanto en las transferencias, sino en la necesidad de recibir unos aviones que no llegaron nunca, aunque sí lo hicieron los de la Legión Cóndor para arrasar Guernica. Y aunque nos consta que para Indalecio Prieto uno de los días más tristes de su vida fue el de la caída de Bilbao, poco pudo hacer para paliar aquella deficiencia", Iñaki Anasagasti Olabeaga, en DSCD-1986-003 23/7/86.

24. "Acaban de cumplirse sesenta y dos años desde que Guernica fue arrasada y destruida por las tropas franquistas. Hemos querido hacer un homenaje y restituir el honor de aquellos llamados rojos separatistas a los que el régimen de Franco calumnió haciéndoles culpables de la destrucción de Guernica, cuando nadie tenía duda, entonces y hoy, de la autoría de la masacre por parte de la Legión alemana Cóndor, a las órdenes del general Franco. Reconocido este hecho por todos y por la historia, ningún gobierno español ha desmentido oficialmente aquella calumnia, por lo que pedimos hoy al Gobierno español que sea el que oficialmente reconozca que el bombardeo de Guernica el 23 de abril de 1937 fue realizado por la Legión Cóndor y no por los rojos separatistas", Jon Zabalía Lezamiz, en DSCD-1999-249 23/6/99.

25. "[Ante el nacimiento de la OTAN] Esa fue nuestra actitud inicial a través de la cual teníamos la confianza de que el régimen de Franco, colaboracionista de Hitler y Mussolini, desde luego no neutral, cayera. Nuestras aspiraciones se vieron truncadas y la frustración se apoderó de todos los demócratas; la liberación de Europa no nos liberó, por lo que tampoco nos beneficiamos del Plan Marshall, clave de la recuperación económica europea", Andoni Monforte Arregui, en DSCD-1986-267 5/2/86. 
los partidos republicanos en el exilio por no haberse aceptado su exigencia de autodeterminación para Euskadi. Con todo ello, el PNV se alineó con las tesis que propugnaba la JEL ${ }^{26}$.

En la década de los ochenta, se abrió para España el periodo de integración en las estructuras internacionales. El ingreso en la OTAN en 1982 y la incorporación al proyecto europeo contaron con el apoyo mayoritario del espectro político. El Partido Nacionalista Vasco volvía a hacer gala de su carácter europeísta y así, en 1984 mostraba al resto de partidos que el PNV podía hablar de la incorporación de España a la CEE desde la posición de un partido que participó desde el exilio en el proyecto de construcción europea ${ }^{27}$. Era una tradición europeísta que ya venía de antiguo como señalaba Iñaki Anasagasti ${ }^{28}$, y desde esa posición protagonista dentro del movimiento europeo, en 1988, con ocasión de la próxima presidencia del Consejo de las Comunidades Europeas de turno para España, el PNV aconsejó a Felipe González retomar el espíritu original de Europa $^{29}$.

26. "Se nos podrá decir que no es bueno mirar hacia atrás. Sin embargo, si hoy discutimos este Convenio [Convenio entre el Reino de España y los Estados Unidos de América sobre Cooperación para la Defensa] es, en gran parte, porque un malhadado día de 1953 España se alquiló a precio de saldo porque aquí había una dictadura y porque los Estados Unidos apostaron por un dictador, ni más ni menos. Esa decisión fue especialmente dolorosa. Era toda una generación de la Guerra Civil, la que había colaborado en la Segunda Guerra Mundial con los aliados, la que en San Francisco y en la ONU había logrado aislar al régimen de Franco, la que vio estupefacta cómo se quedaron solos y olvidados, quizá porque despertaron vergüenzas inoportunas: los principios estaban por debajo de las bases militares. Comprendemos el desaliento de aquellos hombres y mujeres que en 1951 hicieron una huelga general para demostrar al Gobierno de los Estados Unidos que aquí existía una alternativa organizada frente a la dictadura franquista y se encontraron con la desagradable sorpresa del Almirante Sherman conversando con Franco en Madrid", Iñaki Anasagasti Olabeaga, en DSCD-176-1989 9/3/89.

27. "[venimos de] un Partido europeísta; de un Partido que estuvo en la cumbre de La Haya, en la que estaba representado en aquella época José Antonio Aguirre, lendakari en el exilio, y otras personas de nuestro Partido; de un Partido que estuvo invitado a la cumbre de Mesina; de un Partido que ha sido siempre europeísta", Jon Gangoiti Llaguno, en DSCD-1984098 29/2/84.

28. "Cuando muy pocos hablaban de Europa, en 1932, el Partido Nacionalista Vasco organizó su 'Aberri Eguna bajo el lema de' Euzkadi-Europa". Nuestra gente salió masivamente a la calle detrás de aquel lema. ¿Qué intuyeron para mirar tan claramente hacia Europa? Posteriormente, José Antonio de Aguirre, Manuel de Irujo, Javier de Landaburu, José María de Lasarte, Jesús María de Leizaola y Juan de Ajuriaguerra, entre otros, participaron de manera muy directa en el exilio en el movimiento europeo, hasta el punto de que el Consejo Federal del Estado español del movimiento europeo se formó en la delegación del Gobierno vasco en París en 1948, siendo elegido allí su presidente Salvador de Madariaga", Iñaki Anasagasti Olabeaga, en DSCD-1986-003 23/7/86.

29. "Hace cuarenta años, un grupo de exiliados, considerados chiflados, en la Delegación del Gobierno Vasco en el exilio de París, formaron un Consejo y eligieron a don Salvador de Madariaga como su presidente. Allí había socialistas republicanos y nacionalistas catalanes y vascos. Posteriormente se integraron otros grupos. Es decir, usted será presidente de la Comi- 
Al conmemorarse el $50^{\circ}$ aniversario del exilio español en 1989, apenas fue mencionado en las intervenciones de los diputados ${ }^{30}$, pero si fue recordado por parte del PNV, aunque no fue para evocar el aniversario ni para rememorar a los exiliados, sino que la referencia iba dirigida al papel político que jugó el PNV desde el exilio. El gobierno provisional vasco en el exilio estuvo lejos de conseguir sus objetivos de reconocimiento internacional. Desde el exterior promovió diversas huelgas hasta 1951 y llegó a participar en el Congreso de La Haya. Por ello, el PNV volvió a presentar al Gobierno Vasco en el exilio como protagonista indiscutible en aquel proceso de construcción europea ${ }^{31}$. La lucha antifranquista del PNV fue mostrada desde la perspectiva internacional y europeísta ante la falta de resultados en la lucha interior enfocada directamente a poner fin al régimen franquista desde dentro. Una lucha con decepcionantes resultados pero que supone un importante aval de legitimación antifranquista y democrática para la historia del partido. Por ello, el PNV se reivindica como uno de los partidos con mayor tradición antifranquista, alineándose junto a los partidos con mayor proyección en la oposición a la dictadura, -PSOE y PCE- a la vez que se separan ideológicamente del PP, partido que hegemoniza la derecha española en esas legislaturas ${ }^{32}$.

EI PNV ha sido acusado en diferentes momentos de cierta connivencia con la banda terrorista por aprovecharse políticamente de la acción violenta de ETA ${ }^{33}$.

sión cuando se celebren los cuarenta años de una reunión en la que aquellos hombres planteaban una Europa federal en línea con los enunciados de Schuman, De Gasperi, Adenauer, Spaak y Monnet. Por eso me atrevo a sugerirle que, además de sus planteamientos técnicos sobre Europa, retome la idea original de aquellos hombres, que jamás hubieran pensado que cuarenta años después usted tendría la magnífica oportunidad, por lo menos, de plantear en democracia sus ideas", Iñaki Anasagasti Olabeaga, en DSCD-1988-089 25/2/88.

30. Sobre el uso público del pasado y la política de baja intensidad conmemorativa en el periodo socialista véase Abdón MATEOS LÓPEZ: Historia del antifranquismo, Barcelona, Ed. Flor del viento, 2011, pp. 215-226.

31. "Hace una semana se cumplieron cuarenta años de la creación en Park del Consejo Federal del Estado Español del Movimiento Europeo. Aquella convocatoria fue realizada por Salvador de Madariaga y José Antonio de Aguirre. Y las dos reuniones, a las que asistieron representantes de su Partido, tuvieron lugar en la sede de la delegación vasca en el exilio", Iñaki Anasagasti Olabeaga, en DSCD-1989-167 15/2/89.

32. "...algunos [PP] han pretendido darnos lecciones de sensibilidad con los derechos humanos y libertades públicas nada menos que a los tres Partidos, a los tres Grupos Parlamentarios que en este momento poseen en esta Cámara mayor tradición histórica de lucha por los derechos fundamentales y libertades públicas; lecciones de lucha por la democracia a los tres Grupos Parlamentarios que tienen en este momento seguramente en su tradición histórica más presos por la lucha y por el devenir de la democracia en este país, que tienen seguramente más muertos en la lucha por este objetivo, que tienen seguramente más exiliados y que han dejado más partes ínsitas de sí mismos en el camino de la consecución de la democracia", Emilio Olabarría Muñoz, en DSCD-1991-149 26/11/91.

33. José Luís de la GRANJA SAINZ: "Luces y sombras en la historia del Partido Nacionalista Vasco. Comentarios sobre el péndulo Patriótico", Pasado y Memoria. Revista de Historia 
Como se ha apuntado anteriormente, el PNV no reconoció el carácter terrorista de ETA hasta bien avanzada la democracia. Fue en el año 1986, -coincidiendo con los pactos entre PNV y PSOE- cuando por primera vez el PNV se refiere en sede parlamentaria a las acciones de ETA como "terrorismo", como destacaba el diario El País en su edición de 24 de julio de $1986^{34}$. Para el PNV, la violencia de ETA supuso, por una parte, un hecho condenable y muy perjudicial para la sociedad vasca ${ }^{35}$, y por otra, una más de las manifestaciones del "irresoluble problema vasco". Según el PNV, la lucha contra ETA había de abordarse teniendo en cuenta la globalidad del sentimiento independentista de los vascos como decía Iñaki Anasagasti citando palabras de Azaña ${ }^{36}$.

\section{El triunfo de los populares. 1996-2004}

Las elecciones generales de 1996 dieron el triunfo por vez primera al Partido Popular de José María Aznar que logró gobernar con una mayoría simple y con acuerdos de legislatura con los nacionalistas catalanes, vascos y canarios. Esto supuso un incremento de la financiación autonómica y un traspaso de transferencias autonómicas al gobierno vasco. Aparentemente, existió un buen entendimiento entre PNV y PP durante el primer año de legislatura, algo que terminó

Contemporánea, 1, (2002), pp. 5-26, esp. pp. 21-22. Sobre la ambigua actitud del PNV ante el terrorismo de ETA véase Roberto MUÑOZ BOLAÑOS: "El nuevo Estado democrático frente al desafío terrorista", en Gaizka FERNÁNDEZ SOLDEVILLA y María JIMÉNEZ RAMOS (Coords.): 1980. El terrorismo contra la Transición, Madrid, Tecnos, 2020, pp. 227-253, esp. pp. 236-237.

34. “...González respondió al líder conservador que el terrorismo no sólo se combate con medidas legales y advirtió que algunas de las propuestas de Fraga podrían ser consideradas inconstitucionales. El representante del PNV, Anasagasti, empleó ayer por primera vez en la historia de su grupo parlamentario el término "terrorismo" para referirse a las acciones de ETA", en Diario El País, 24-07-86, https://elpais.com/diario/1986/07/24/ [Consultado 03/02/2021]

35. "quien más sufre esta violencia asfixiante, que debería estar en el basurero de la historia, además de las víctimas y de las familias que directamente la padecen, es el propio pueblo vasco, al que le ensucian su nombre, al que le identifican con unas siglas de muerte, al que le condenan a la ruina económica, al que le crean tal desasosiego que le imposibilita enfrentar su futuro con la serenidad", en Iñaki Anasagasti Olabeaga, en DSCD-003-1986 23/7/86.

36. "Le pedimos no olvide que el conflicto histórico vasco es de origen y naturaleza política y que, si queremos una normalización eficaz, tenemos que abordar todos los puntos del contencioso. El problema no es solamente ETA. Lo decía el propio Manuel Azaña hace sesenta años. No se puede detener un torrente con una espada. [...] Hace sesenta años, su admirado presidente Manuel Azaña, tras aquella inmensa tragedia, hizo un llamamiento que no fue escuchado - cayó en el vacío-. Ojalá lo sea ahora y permítame esa osadía de traer aquí las palabras de Manuel Azaña. Decía aquel presidente vencido: Abrigados en la tierra materna, ya no tienen odio, ya no tienen rencor y nos envían con los destellos de su luz, tranquila y remota como los de una estrella, el mensaje de paz, piedad y perdón. Ojalá hoy en día tengan valor estas palabras", Iñaki Anasagasti Olabeaga, en DSCD-248-1999 22/6/99. Para profundizar sobre la interpretación histórica del PNV del "conflicto vasco" véase Manuel MONTERO GARCÍA: "La historia y el nacionalismo...", pp. 247-276. 
tras las negociaciones del PNV con la banda ETA en 1998 y que se tradujo en una tregua que duró aproximadamente un año ${ }^{37}$.

El uso del pasado como arma política en el Congreso de los Diputados llegó a ser casi testimonial en estos años de la primera legislatura popular, más baja aún que de lo habían sido durante la Transición y los catorce años de gobiernos socialistas. Únicamente el PSOE en la campaña electoral de 1996 y desde la oposición abría el debate resucitando la idea del pasado franquista del Partido Popular, partido que apelaba por entonces a la Transición como ariete contra las pretensiones de resucitar el recuerdo de nuestro pasado, un pasado que debía ser olvidado anteponiendo la evocación de una Transición modélica que zanjó definitivamente el enfrentamiento de las dos Españas. Para el PNV, el año 1999 fue el año del desencuentro con el Partido Popular al que acusaba de no haber cumplido con sus compromisos en relación con el País Vasco y así, en la sesión que debatía el Estado de la Nación, contrarrestaba esa imagen idílica de la Transición que presentaba el PP aduciendo que para ellos no tuvo nada de modélica la transición a la democracia ${ }^{38}$. La única alusión en esta legislatura a la Guerra Civil por parte del PNV vino de la mano de Jon Zabalía, que ante la discusión sobre el envío de tropas españolas a Kosovo en 1999, mostraba el acuerdo del PNV con esa misión militar y señaló para ello el contraejemplo de la política de no intervención de los países democráticos en la Guerra Civil que hizo posible la victoria de Franco ${ }^{39}$.

Pero todo esto era algo que cambiaría drásticamente en la segunda legislatura del gobierno del PP. Ahora sí con mayoría absoluta, ya no necesitaba los apoyos nacionalistas catalanes ni pactos con partidos nacionalistas en las comunidades autónomas. Era la hora de emplear la herramienta del pasado que ya iniciaron los socialistas en la campaña electoral del año 1996. Y con el cambio de siglo se utilizaría con mayor intensidad que durante las dos primeras legislaturas democráticas, ahora también como arma política. Pero en relación con el $\mathrm{PNV}$, hay que tener en cuenta que el cambio en sus directrices políticas, tuvo que ver con la situación en la que se encontraba Euskadi, sobre

37. Véase José Luís de la GRANJA SAINZ: "El error de Estella del PNV en perspectiva histórica", Anales de Historia Contemporánea, 16 (2000), pp. 199-207.

38. "La transición fue posible porque no se miró al pasado ni se cobraron facturas. [...] Le pedimos se acuerde [a Aznar] que la transición de la feroz dictadura de Franco a la actual democracia se logró porque los vencidos en aquella contienda no pasaron factura moral alguna. ¡Tanto hablar de la transición y de su modelo para otras situaciones y no parecen capaces de recordar algo tan obvio y tan cercano!", Iñaki Anasagasti Olabeaga, en DSCD-248-1999 22/6/99.

39. "Sin embargo, con lo que no estamos de acuerdo es con que la OTAN no intervenga. Tenemos todavía muy presente lo que ocurrió en la guerra civil española, que con un comité de no intervención hizo posible el triunfo de Franco por 40 años. Por esta razón, señores de Izquierda Unida, nosotros no vamos a apoyar su iniciativa", Jon Zabalía Lezamiz, en DSCD1999-230 20/4/99. 
todo la repercusión que tuvieron las movilizaciones que se realizaron durante el cautiverio y posterior asesinato de Miguel Ángel Blanco en 1997, que llevó a la sociedad vasca a unas jornadas de movilización sin precedentes, en las que muchos ciudadanos vascos perdieron el miedo contenido durante muchos años y dirigieron su rabia no sólo contra ETA y Herri Batasuna sino también contra el nacionalismo gobernante ${ }^{40}$. La lección que el Partido Nacionalista Vasco sacó de aquellas jornadas fue la de que una política antiterrorista eficaz dirigida contra ETA y sus cómplices iba a resquebrajar la hegemonía nacionalista, por lo que decidió variar su rumbo y enfilar hacia la realización de negociaciones con ETA y otros partidos nacionalistas que condujeron finalmente en 1998 al Pacto de Estella con $\mathrm{HB}$, pero también con $\mathrm{ETA}^{41}$ y que reflejó lo que iba a ser la posición del PNV en el Congreso de los Diputados a partir de entonces. La política nacionalista pendular del partido viró hacia posicionamientos más radicalizados cuya consecuencia política más evidente fue el denominado "Plan Ibarretxe" que pretendió una reforma del Estatuto que posibilitara al País Vasco aspirar a su autodeterminación ${ }^{42}$.

La confrontación con el PP se hizo más evidente cuando en 2001 el PNV presentó una Proposición no de Ley sobre condena del alzamiento militar del 18 de julio de 1936 contra el régimen legítimo de la II República. El PP incluyó una enmienda introduciendo a ETA en su argumentación que el PNV rechazó y con los votos populares la proposición no se aprobó. González de Txabarri que defendía la proposición, recriminó al gobierno por no querer honrar la memoria de los republicanos ${ }^{43}$ y por querer hacer una política de sociología franquista ${ }^{44}$. Meses más tarde, en el debate del estado de la nación, Iñaki Anasagasti acusaba

40. Carmen GONZÁLEZ MARTíNEZ: "Recuperar la memoria y el pasado histórico para comprender el presente de Euskadi", Anales de Historia Contemporánea, 20 (2004), pp. 507514, esp. p. 512.

41. Eduardo VÍRGALA FORURIA: "La reforma territorial en Euskadi: los Planes Ibarretxe I (2003) y II (2007)", Cuadernos Constitucionales de la Cátedra Fadrique Furió Ceriol, 54/55 (2006), pp. 159-187, esp. p. 161.

42. Sobre la política pendular del PNV véase: Santiago de PABLO y Ludger MEES: El péndulo patriótico. Historia del Partido Nacionalista Vasco (1895-2005), Barcelona, Crítica, 2005.

43. "El Grupo Parlamentario Vasco comprueba que cualificados dirigentes políticos de la dictadura se han sacudido los complejos, si alguna vez los tuvieron, e imparten clases de democracia a diestro y siniestro [...] Nada honra a los caídos por la República ni a los republicanos que, presos, fueron obligados a construir tamaña mole faraónica y que allí murieron de frío y de hambre en trabajos forzados...", José Juan González de Txabarri, en DSCD-059-2001 13/2/01.

44. "Observa el Grupo Parlamentario Vasco, señorías, entre indignado y sorprendido, múltiples actitudes políticas obstinadas en resucitar fantasmas del pasado, de un pasado negro, abyecto, fascista y antidemocrático. [...] Veinticinco años después, señorías, la España sociológicamente franquista da la impresión de que quiere volver por sus fueros, que suspira y añora la España una, grande y libre", José Juan González de Txabarri, en DSCD-059-2001 $13 / 2 / 01$ 
al gobierno de José María Aznar de incumplir sus acuerdos y de tratar al PNV como parte del bando perdedor de la guerra, toda vez que no se le había devuelto el patrimonio incautado, porque para ellos, el partido seguía formando parte del bando republicano ${ }^{45}$. Se volvía de nuevo a reclamar la devolución de las propiedades incautadas al PNV durante la Guerra Civil tras décadas de olvido.

Así, las acusaciones al Partido Popular se repitieron a lo largo de los siguientes años de gobierno de José María Aznar. En particular el PNV incidió, de una forma especial, en la reiterada negativa a que la Cámara condenara el golpe de estado de 1936 por parte del Partido Popular ${ }^{46}$, partido que aludía a la peligrosidad que suponía remover el pasado, un recuerdo traumático del pasado que estaba ya cerrado desde la Constitución de 1978. Por el contrario, al PNV se le reprochaba pactar con partidos de izquierdas y de derechas según su conveniencia, acusación que el partido sufría ya desde la República. EI PNV contrarrestaba con un hilo argumental en el que se va dibujando una imagen de partido que ha tenido que luchar contra los posicionamientos de la derecha y también contra partidos de izquierda para la consecución de sus objetivos soberanistas como decía Josu Erkoreka refiriéndose a los ataques que, en la II República, le lanzaban desde los dos lados del arco parlamentario. Por una parte, los socialistas entonces recriminaban al PNV vender el País Vasco a la Iglesia Católica y por otra parte, desde la CEDA, Gil Robles les acusaba de desleales con el mundo católico ${ }^{47}$.

José Juan González de Txabarri también protestó porque, debido a la inacción gubernamental, aún seguía presente la exhibición de simbología de militares golpistas que participaron en la Guerra Civil y sobre la Basílica del Valle de

45. "Hace cinco años el Grupo Parlamentario Vasco votó su investidura. Usted se comprometió a actualizar el concierto, financiar la formación continua y devolver el patrimonio incautado con motivo de la guerra. Hoy, en el mes de junio, el concierto está sin renovar. Quizás ustedes pensaron que hubiera sido mejor negociar estas cosas con ustedes mismos y sin respeto institucional lo han paralizado de momento todo. [...] Finalmente, en relación con la devolución del patrimonio incautado con motivo de la guerra, se nos sigue aplicando a nosotros y a todos los perdedores de la guerra del 36 el baremo de vencidos", Iñaki Anasagasti Olabeaga, en DSCD-2001-095 26/6/01.

46. "Una transición basada en la impunidad y en las loas continuas al perdón de los responsables de aquella tragedia ha hecho que su grupo parlamentario [Grupo Popular], este año, una vez más, se haya negado a condenar aquella sublevación y hoy es el día en el que todavía en esta Cámara no se ha condenado aquel baño de sangre...", Iñaki Anasagasti Olabeaga, en DSCD-2001-095 26/6/01.

47. "Fíjense, durante la II República, mientras Indalecio Prieto nos acusaba de querer vender el País Vasco a la Iglesia católica, convirtiendo Euskadi en una especie de Gibraltar vaticanista - y la expresión no es mía, es suya-, Gil Robles, desde el otro extremo del arco parlamentario, nos acusaba de ser profundamente desleales con el mundo católico por pactar y colaborar con rojos y comunistas. ¡Qué se le va a hacer! Son paradojas de la política", Josu Erkoreka Gervasio, en DSCD-2002-168 4/6/02. 
los Caídos que solo honra a los caídos del bando ganador ${ }^{48}$. En febrero de 2002, Josu Erkoreka seguía planteando, en nombre de la sociedad española, una condena explícita que todavía el Congreso no había podido conseguir: "...la militancia democrática exige hoy en España no abandonar la perspectiva histórica; exige participar de la cultura antifranquista; exige condenar el alzamiento militar del 18 de julio... ${ }^{49 " Y}$ unos meses más tarde, en julio de 2002, Anasagasti volvía a recordar a José María Aznar que "tenemos que decir que usted y su partido no han querido condenar en esta Cámara aquella sublevación militar contra un Gobierno legítimo nacido de una Constitución republicana legítima ${ }^{50 "}$.

Tras el fracaso del Pacto de Estella, el fin de la tregua de ETA y de las nulas opciones de aprobación del Ilamado Plan Ibarretxe ${ }^{51}$, las menciones que el PNV realizó en relación con el nacimiento de ETA tuvieron que ver, en primer lugar, con la justificación de su creación y de su lucha antifranquista y por otra parte con el rechazo a sus acciones violentas, alineándose así con el resto de las fuerzas democráticas. Para el partido, el nacimiento de ETA fue consecuencia necesaria de la política represiva de la dictadura hacia "el problema vasco", como decía el PNV en el Congreso en 2001, "...aquí hubo una dictadura de 40 años, cuyos coletazos todavía vivimos, porque el único culpable del nacimiento de ETA fue el régimen de Franco ${ }^{52 "}$. Y reiterado un año después, "Hubo una dictadura que creó a ETA. En el año 1960 surge ETA, que mata en aquellos años... "53. Era una represión contra "lo vasco" que, para el PNV se mantuvo hasta los últimos gobiernos franquistas y también durante la Transición a la democracia en 1976 con sucesos como los de Montejurra, Vitoria o el asesinato de Normi Mentxaca a manos de un guerrillero de Cristo Rey amparado por la policía, que Iñaki Anasagasti recordaba dirigiendo hacia Manuel Fraga la acusación de asesinato de 5 trabajadores en Vitoria en 1976 siendo ministro franquista de la Gobernación ${ }^{54}$. Y que, por tanto, "debía rechazarse contundentemente la injus-

48. "Veinticinco años después, en ciertas zonas de España, todavía se exhiben símbolos y monumentos que rememoran en lugares céntricos y destacados de dichas localidades acontecimientos golpistas, ideologías totalitarias y personajes fascistas. El Valle de los Caídos es basílica y necrópolis erigida en memoria de los caídos por Dios y por España, caídos durante la guerra civil, pero sólo los del bando franquista. Nada honra a los caídos por la República", José Juan González de Txabarri, en DSCD-2001-059 13/2/01.

49. Josu Erkoreka Gervasio, en DSCD-2002-139 19/2/02.

50. Iñaki Anasagasti Olabeaga, en DSCD-2002-179 15/7/02.

51. Para ampliar información sobre estos temas véanse: José Luís de la GRANJA SAINZ: "El error de Estella del PNV..."; Alberto PÉREZ CALVO: "El plan Ibarretxe y su grave déficit democrático de partida", Revista de Estudios Políticos (Nueva Época), 126 (2004), pp. 9-28.

52. Iñaki Anasagasti Olabeaga, en DSCD-095-2001 26/6/01.

53. Iñaki Anasagasti Olabeaga, en DSCD-179-2002 15/7/02.

54. "Para usted [José María Aznar] no existió Montejurra ni Normi Menchaca ni los terribles sucesos del 3 de marzo de 1976, en los que fueron asesinados en Vitoria 5 trabajadores, cuando Manuel Fraga era ministro de la Gobernación. Sabemos que las víctimas son las de 
ta represión y los múltiples excesos que se cometieron durante el ignominioso régimen del generalísimo Franco ${ }^{\prime \prime 55}$

El recuerdo de la Guerra Civil para el PNV se hizo presente también en la postura que adoptó de forma reiterada ante las propuestas de los partidos políticos con ocasión de reconocimiento de las víctimas, su reparación y las medidas conducentes a la recuperación de una memoria histórica que defina de una forma realista lo acontecido para contrarrestar el revisionismo histórico que, a su entender, se realizaba desde posiciones de la derecha española más retrógrada ${ }^{56}$. Por ejemplo, se hizo un paralelismo de lo acontecido en 1937 en el País Vasco con la pretensión del Gobierno del envío de tropas españolas con motivo de la guerra de Irak, donde se hace una crítica a la intervención de las fuerzas armadas españolas junto con tropas americanas y británicas ${ }^{57}$. Esta utilización del recuerdo de la guerra se manifestaba en otras ocasiones con la narración de hechos bélicos como el avance franquista hacia Cataluña al hacer un relato pormenorizado del consejo de guerra que dictaminó el fusilamiento de Companys ${ }^{58}$.

ETA, en su mayor volumen y de una manera percutiente — casi mensualmente-...,", Iñaki Anasagasti Olabeaga, en DSCD-179-2002 15/7/02.

55. Josu Erkoreka Gervasio, en DSCD-139-2002 19/02/02.

56. “...se producen sorprendentemente entre nosotros todavía auténticas apologías de la desmemoria, planteamientos que pretenden tender un oscuro manto sobre el pasado, argumentando siempre erróneamente, pero a veces incluso también cínicamente, que la historia es sólo un lastre que impide encarar el futuro con posibilidades de éxito. Un documento doctrinal recientemente aprobado en el seno de una organización política muy relevante en el Estado llega a afirmar literalmente que las nuevas generaciones no se merecen que los nuevos retos que tiene planteados España sean abordados con viejas ideas, con viejos prejuicios y agravios, con viejas historias", Josu Erkoreka Gervasio, en DSCD-2002-139 19/2/02.

57. "La verdad es que ayer se conmemoró el $66^{\circ}$ aniversario del bombardeo de Durango, y al poco tiempo se produjo el bombardeo de Gernika, el 26 de abril de 1937, con una masacre que tenía fundamentalmente por objeto aterrorizar a la gente. Sesenta y seis años después estamos ante una situación similar: se pretende aterrorizar a los iraquíes...", Iñaki Anasagasti Olabeaga, en DSCD-2003-240 1/4/03.

58. "El propio general Queipo de Llano, en una charla, señaló: Companys ha dejado salir de Barcelona a más de 5.000 hombres de derechas, lo cual ha de aminorar sin duda la responsabilidad que pesa sobre él. Esa responsabilidad no fue disminuida, porque se le condena a muerte, después de ser capturado a traición, en un consejo de guerra del que ahora hemos sabido más detalles gracias a la aparición hace poco tiempo de su abogado defensor, un abogado defensor de oficio, un capitán de artillería, Colubí, una persona a la que le conmutan la pena por haberse alzado en armas y es entregado en un canje al ejército franquista. Él combate en la batalla del Ebro y después entra con Franco en Barcelona y le toca defender a Companys; en 1947 se exilia a Venezuela. Él dice: A mí me tocaba cubrir las apariencias para que el proceso de Companys pareciera legal, cuando todos sabíamos que aquello respondía a una orden concreta de Franco para que fuera fusilado. En unas pocas horas tuve que redactar el escrito de defensa. Fui a ver a Companys: Usted me conmutó la pena, haré todo lo que pueda para salvarle la vida. Alegó esos gestos de Companys en su momento, pero no sirvieron de nada. Tampoco ese relato de Queipo de Llano que he mencionado antes. Fue condenado 
La clase política del final de siglo XX, parecía mostrar un interés creciente en recuperar desde las instituciones una mirada más plural hacia el pasado reciente que hiciera visible los olvidos de la mitad de la sociedad que perdió la guerra. EI PNV se sumó de una forma activa a esa reactivación promovida desde los sectores de la izquierda española y desde partidos nacionalistas minorita$\operatorname{rios}^{59}$. Era un esfuerzo de recuperación que contaba con la oposición rotunda del PP, hasta que se consiguió finalmente una condena al golpe de 1936 y un reconocimiento hacia las víctimas de la Guerra Civil consensuada por todos los grupos parlamentarios en 2002, -incluido el PP- hecho éste que aplaudió el PNV ${ }^{60}$. Pero el Partido Popular, con esa resolución, daba por zanjado el tema en torno a estas cuestiones, no así el resto de los partidos, incluido el PNV, que no consideraban la resolución como un punto final, sino como una puerta abierta hacia las políticas de reparación histórica que seguían contando con el rechazo frontal del PP, el cual consideraba que lo acordado en dicha comisión dejaba zanjado cualquier iniciativa sobre el pasado, recuerdo al pasado que es innecesario puesto que ya la Constitución y las leyes de amnistía cerraron ese episodio traumático de la guerra.

En cuanto al pasado dictatorial, el PNV recordaba que ya desde la temprana posguerra, el gobierno de Franco pretendía poner a España al nivel de potencias como Francia y Gran Bretaña en cuanto a política internacional después de que la II República, según el relato del régimen, dejara prácticamente sin existencia una política diplomática al país ${ }^{61}$. Por otro lado, la pretensión del derrocamiento

curiosamente por adhesión a rebelión militar. Es curioso que precisamente en el proceso del general Batet que les he mencionado antes, que fue el que reprimió el levantamiento de 1934, muchos defensores no querían aceptar a personas que querían designarles...", Aitor Esteban Bravo, en DSCD-034-2004 28/9/04.

59. “...durante los últimos años estamos asistiendo a un saludable despertar del interés por recuperar la memoria colectiva. Los ciudadanos no dejan de explorar nuevas fórmulas para dirigir una mirada crítica al pasado, no con un afán meramente especulativo ni con ánimo de revancha, sino con la firme determinación de hacer justicia, de hacer justicia, primero, con las víctimas de la guerra civil", Josu Erkoreka Gervasio, en DSCD-2004-013 1/6/04.

60. "Durante la VII Legislatura se presentaron muchas iniciativas tendentes a recuperar la memoria histórica, iniciativas que perseguían evaluar críticamente el pasado político reciente y reparar moral y económicamente a las víctimas de la guerra civil [...]Muchas de ellas sucumbieron, como es sabido, a la negativa rotunda que el Grupo Popular impuso absolutamente a lo largo de la pasada legislatura, pero finalmente, el 26 de noviembre del año 2002, la Comisión Constitucional consiguió aprobar por unanimidad una resolución que afirmaba un reconocimiento moral claro a todos los hombres y mujeres que fueron víctimas de la guerra civil española", Josu Erkoreka Gervasio, en DSCD-2004-013 1/6/04.

61. "Señor presidente del Gobierno, en la temprana postguerra, dos ilustres vascos, Areilza y Castiella, por encargo del régimen, en aquella época escribieron un libro que se titulaba Reivindicaciones de España. Otro vasco, también ilustre, el falangista Valdés Larrañaga, afirmó muy gráficamente en relación con aquel libro que era el Mein Kampf de la política española. El libro partía del presupuesto de que, durante décadas, en España prácticamente no había habido política internacional y que, de alguna manera, la España triunfante e imperial que 
de la dictadura no contemplaba para el PNV una intervención militar exterior. En 2003, en la sesión que debatía sobre el envío de tropas españolas a Irak, hizo un paralelismo con la acción antifranquista de los años cuarenta, señalando que entonces no se planteaba una invasión internacional para derrocar al régimen dictatorial ${ }^{62}$.

Un cuarto de siglo después de la muerte de Franco, el periodo de transición a la democracia empezó a verse como un episodio deliberado de amnesia respecto al pasado reciente de España. EI PNV se cuestionaba el modelo y la perspectiva con la que se encaró el tránsito de la dictadura a la democracia, en el sentido que el pacto implícito entre las élites políticas franquistas y los partidos recién legalizados tuvo como condición el olvido de las responsabilidades y atrocidades de la contienda ${ }^{63}$ y también en palabras de Margarita Uría: "...la transición, siempre tachada de modélica, no lo fue tanto y que no hay que echar en el olvido ni hacer pactos de no mirar hacia atrás. Yo creo que no debe haber vaciado de memoria" ${ }^{64}$. Contraponiendo ahora que, la imagen idílica que preconizaba el Partido Popular sobre la Transición no fue tal puesto

había ganado la guerra civil iba, por fin, a retomar las riendas de la acción exterior del Estado, situando al Estado a la altura que le correspondía, a la altura de los grandes. Entonces se pensaba situarlo a la altura, por lo menos, de Gran Bretaña y de Francia, y, por supuesto a la altura de Alemania, que era el país que entonces estaba de moda", Josu Erkoreka Gervasio, en DSCD-020-2004 23/6/04.

62. "Los numerosos hijos de prebostes franquistas que aplauden esta guerra con el argumento de que la intervención es necesaria para liberar al pueblo iraquí de una dictadura olvidan que la España de los años cuarenta y cincuenta... ¡Yo no sé por qué se sienten aludidos! Con la derrota del eje del mal todavía reciente en la memoria y en el cine propagandístico de Hollywood, no era precisamente el régimen más presentable en el mundo. Nadie hubiese aprobado sin embargo, ni los antifranquistas más beligerantes, una invasión a pelo de España en el año 1945; cuando los españoles sentían en 1945 y 1946 que arreciaba la presión internacional respondían: Si ellos tienen la ONU, nosotros tenemos dos. ¡Pero todo se olvida, todos se mienten, todo se falsifica! Los marines no desfilaron por la Castellana, desfilaron los generales Franco Bahamonde y Dwight Eisenhower en un coche regalado por Hitler y escoltados por una guardia mora. Tuvimos buena suerte, eso es todo, en lugar de petróleo. Y finalmente, que nadie diga ahora que hubiese preferido la invasión y la guerra —otra guerra en los años cuarenta - a condición de librarse del césar visionario. Había otras maneras de zafarse de él, pero a nadie le interesó ponerlas por obra", Iñaki Anasagasti Olabeaga, en DSCD-238-2003 25/3/03.

63. "Ahora hay quien apuesta por una historia revisionista de la transición, léase al profesor Tussel [sic]. Bueno será el recuerdo y el reconocimiento de casos como el que he citado. Paz, piedad, perdón es la bonita pero también manida frase del presidente Azaña al terminar la contienda. Entonces la paz fue como fue y la piedad y el perdón prácticamente no existieron. Llegados ya a la transición, época a la que la ley se retrotrae, reconózcase que ésta no fue tan modélica, que quizá unos soportaron más que otros y que si no hubo perdón lo que sí hubo es voluntad de reconciliación pero no de amnesia. Apostamos, por tanto, por la superación del pasado, pero no por su olvido", Margarita Uría Etxebarría, en DSCD-2001-103 18/9/01.

64. Margarita Uría Etxeberría, en DSCD-243-2003 8/4/03. 
que se hizo a costa del olvido y la desmemoria de los vencidos y represaliados de la dictadura ${ }^{65}$.

Lo que se proponía al comenzar un nuevo siglo, era deshacer el error cometido décadas atrás e impulsar el recuerdo de las víctimas de la guerra a pesar de los obstáculos ideológicos de la derecha española que, escudada en el peligro de reabrir viejas heridas, se mantuvo en una actitud crítica hacia el resurgimiento de ese intento de recuperación de la realidad histórica. No solo eso, sino que, como ya se ha dicho, desde sectores ideológicamente situados en el conservadurismo más estricto, presentaron una especie de revisionismo de la historia reciente para contrarrestar esas nuevas propuestas. El PNV se unió a esta propuesta a la vez que se desmarcaba del planteamiento de la derecha española ${ }^{66}$.

\section{La democracia ante los nuevos desafíos del milenio. 2004-2015}

En las Elecciones Generales de 2004 los votos dieron la victoria al PSOE de José Luís Rodríguez Zapatero. Las encuestas electorales, que pronosticaban una victoria popular, dieron un vuelco a raíz del rechazo mayoritario social y político a la participación española en la guerra de Irak; a los atentados yihadistas de Madrid y, por la actitud informativa de los dirigentes gubernamentales del PP, que anunciaron que fue la banda terrorista ETA la responsable de los atentados, cuando las investigaciones policiales se dirigieron desde el primer momento

65. “En el Estado español, como se sabe, la transición política a la democracia se cimentó en la desmemoria, se asentó en el olvido y fue sin duda la prudencia la que aconsejó que esto fuera así, una prudencia condicionada en parte por el temor al sable, pero animada al mismo tiempo por la firme determinación de no poner en el camino hacia la libertad más obstáculos que aquellos que fueran imprescindibles. Pero hoy, medio siglo después, podemos decir que carecen de sentido las cautelas que entonces impusieron una actitud tan precavida. La sociedad lo percibe — nosotros lo creemos así - con claridad y probablemente por ello durante los últimos años estamos asistiendo a un saludable despertar del interés por recuperar la memoria colectiva. [...]Durante la VII Legislatura se presentaron muchas iniciativas tendentes a recuperar la memoria histórica, iniciativas que perseguían evaluar críticamente el pasado político reciente y reparar moral y económicamente a las víctimas de la guerra civil y a todos aquellos que durante los 40 años subsiguientes padecieron la represión del franquismo. Muchas de ellas sucumbieron, como es sabido, a la negativa rotunda que el Grupo Popular impuso absolutamente a lo largo de la pasada legislatura", Josu Erkoreka Gervasio, en DSCD013-2004 1/6/04.

66. "Hoy, casi medio siglo después de aprobada la Constitución [sic.] carecen ya de sentido las cautelas que entonces impusieron la desmemoria; antes al contrario, parece llegada la hora ya, parece alcanzado el momento ya de saldar cuentas con el pasado en términos de justicia histórica. Sin embargo, se producen sorprendentemente entre nosotros todavía auténticas apologías de la desmemoria, planteamientos que pretenden tender un oscuro manto sobre el pasado, argumentando siempre erróneamente, pero a veces incluso también cínicamente, que la historia es sólo un lastre que impide encarar el futuro con posibilidades de éxito", Josu Erkoreka Gervasio, en DSCD-2002-139 19/2/02. 
hacia células terroristas radicales islamistas. El PNV logró siete diputados en una legislatura que iba a caracterizarse, entre otros asuntos, por la promulgación de la llamada "Ley de la Memoria Histórica".

Ya hemos visto que en la anterior legislatura de mayoría absoluta del PP, se produjo un interés progresivo hacia el pasado por parte de las fuerzas políticas en general y del PNV en particular. Distintas asociaciones y partidos políticos presionaban al PP para que tomara la iniciativa a la hora de recuperar los cuerpos de las fosas de la Guerra Civil y a la retirada de simbología franquista de las calles. Era un interés que se potenció en esta legislatura tras el anuncio del PSOE de su disposición en profundizar en las medidas de reparación y memoria histórica que la sociedad demandaba y que IU y ERC -grupo clave en la investidura de Zapatero- proponían en el Congreso.

Para el PNV, la dictadura franquista representó, sin duda, el periodo más negro de la historia reciente de España. Fue explícito en calificar el régimen como un gobierno totalitario de corte fascista, que utilizaba una violenta represión contra sus ciudadanos y contra instituciones y organizaciones que no comulgaran con la doctrina oficial implantada. Fusilamientos y juicios sumarísimos, deportaciones en masa, trabajos forzados en régimen de semiesclavitud y represaliados políticos eran las medidas que garantizaban un férreo control sobre la población por parte del Estado, como manifestó el partido con ocasión de la aprobación del proyecto de ley sobre el reconocimiento económico a "los niños de la guerra"67. Era esa una represión que tenía su origen ya desde los primeros momentos de la contienda y que incluía a las identidades vasca y catalana, como señalaba Emilio Olabarría ${ }^{68}$.

El día 1 de febrero de 2005 se debatió la propuesta de reforma del Estatuto vasco derivada del Ilamado "Plan Ibarretxe", que llevaba incluido el derecho de autodeterminación para el País Vasco. La acusación de aprovechamiento de la violencia por parte del PNV para obtener réditos políticos es fuertemente contestada por el partido, negándolo y haciendo ver que esa imputación no es nueva, sino que a lo largo de la historia siempre había existido. Así, señalaba el partido que ya desde la II República se les acusaba de ello ${ }^{69}$ y también en la

67. “...los afectados por juicios sumarísimos que se mantuvieron artificial e ilegítimamente durante 10 años después del año 1939; los batallones de trabajadores en los que estuvieron trabajando en régimen de esclavitud o de semiesclavitud durante muchos años personas no condenadas por sentencia de los tribunales militares; los funcionarios inhabilitados; la incautación del patrimonio a personas y colectivos, como los partidos políticos", Emilio Olabarría Muñoz, en DSC-072-2005 24/2/05.

68. "Millán Astray, comentó en el paraninfo de la Universidad de Salamanca ante don Miguel de Unamuno, su rector, que Cataluña y su lengua y el País Vasco y su lengua son dos cánceres que en España hay que erradicar", Emilio Olabarría Muñoz, en DSCD-156-2006 1/3/06.

69. "Nos acusan de sacar provecho de la presión terrorista [...] Recuérdenlo una vez más; hagan memoria. Gil Robles, la gran vaca sagrada de la derecha española, llegó a afirmar que los diputados vascos habían Ilegado a negociar el Estatuto de Gernika a Madrid con el apo- 
Transición ${ }^{70}$. Y de nuevo volvía a establecer el partido que la transición no fue en absoluto un periodo idílico, sino que se hizo, entre otras cosas, a costa de olvidar a uno de los bandos y de borrar las responsabilidades del otro bando ${ }^{71}$. Así, no duda en calificarla negativamente en reiteradas ocasiones y por diferentes motivos. Uno de ellos fue porque la transición a la democracia se hizo a través de las imposiciones de los dirigentes del régimen ${ }^{72}$, dirigentes franquistas que también se integraron en las nuevas estructuras políticas y administrativas, contribuyendo a paralizar los reajustes críticos con el pasado ${ }^{73}$. Para el PNV, estos fallos en el proceso democratizador tienen la consecuencia de mantener una democracia inmadura, al no haber realizado esos ajustes, y con un sector de la derecha que todavía arrastra cierta herencia franquista, porque critica y entorpece la retirada de simbología franquista; paraliza las medidas de recuperación de memoria histórica de los vencidos y obstaculiza las medidas de reparación de las víctimas del franquismo, o la devolución del patrimonio incautado durante

yo de las metralletas. Así literalmente lo dijo.", Josu Erkoreka Gervasio, en DSCD-065-2005 $1 / 2 / 05$.

70. "Hace 26 años, cuando se aprobó el Estatuto de Gernika [...] asistimos a una campaña altisonante y alarmista muy parecida a esta. También entonces se anunció el Apocalipsis y se encendieron todas las luces de emergencia. También entonces se intentó extender la crispación, la inquietud y el desasosiego. Recuérdenlo, señorías, hagan memoria. También entonces se aseguró entre falsos aspavientos y gestos airados que gracias a la ayuda de ETA se había conseguido arrancar al Estado un estatuto que iba a romper a España por los cuatro costados", Josu Erkoreka Gervasio, en DSCD-065-2005 1/2/05.

71. "Se ha manifestado en esta Cámara hoy una cierta idea idílica de una transición, pero nuestro grupo no tiene una sensación idílica de la transición española. Fue una transición del silencio, una transición en la que muchos tuvimos que mantener determinadas formas. No se reivindicó ni se sacaron temas como el de la memoria histórica no porque no se quisiera, sino porque no era factible en aquellos momentos. Fue una transición con el peso importantísimo de unos poderes fácticos que todavía tenían una presencia fundamental en el Estado, y es un sarcasmo que se diga que se ha honrado a las víctimas de la guerra y a las víctimas de la represión franquista. Eso no ha sucedido y no sucedió, desde luego, en la transición". Aitor Esteban Bravo, en DSCD-2006-222 14/12/06.

72. "tuvimos una transición en la que, [...] no hubo comisiones de la verdad, no se destituyó a jueces, policías, etcétera, de su cargo, aun habiendo estado implicados de manera muy intensa en la represión. En definitiva, no hubo ruptura y eso quiere decir que hay una continuidad jurídica del Estado. [...] Con eso no estamos diciendo que el Estado actual tenga nada que ver en su funcionamiento, en su ser, con el régimen franquista, lo que estamos diciendo es que no hubo una ruptura, sino una transición, un continuo jurídico, una herencia del régimen anterior", Aitor Esteban Bravo, en DSCD-152-2006 21/2/06.

73. "la transición tan alabada por tantos se hizo en términos más favorables para unos que para otros. [...] Todos recordamos que para recuperar la democracia se puso en nómina a muchos franquistas, muchos procedentes del Movimiento, de los sindicatos verticales. No viene mal señalar que el ahora senador, señor Fraga Iribarne, en su despedida en Galicia pidió perdón por los errores que hubiera podido cometer durante la democracia, pero no por las barbaridades que pudo perpetrar durante la dictadura y tampoco durante la transición a la democracia", Margarita Uría Etxeberría, en DSCD$153-2006$ 22/2/06. 
la Guerra Civil ${ }^{74}$, en definitiva lo calificaban como un revisionismo histórico del franquismo por parte de estos sectores ${ }^{75}$.

Con la victoria del Partido Popular en 2011, Mariano Rajoy fue investido presidente del Gobierno en un país sumido en una profunda crisis económica, que derivó en una crisis política que emergería años más tarde y que llevaría a la irrupción de nuevos partidos que pusieron fin al bipartidismo imperfecto que había caracterizado al periodo democrático español hasta entonces. Durante esta legislatura se primaron las iniciativas económicas por encima de aspectos más políticos. No obstante, se produjo, entre otras cosas, un desmantelamiento de las medidas recogidas en la "ley de memoria histórica" al dejarla prácticamente sin partida presupuestaria. El debate sobre el pasado quedó relegado a un segundo plano a pesar de las intenciones de partidos de izquierda y nacionalistas que, como el PNV, sacaron a relucir en diversos momentos el recuerdo del pasado.

Con ocasión del $70^{\circ}$ aniversario de la liberación del campo de exterminio de Mauthausen, el PNV recordaba que la represión franquista no solo fue constante durante la dictadura en territorio nacional, sino que también se alargaba fuera de las fronteras, gracias a la colaboración española con la Alemania nazi, y evocaba el internamiento de exiliados españoles en campos de concentración alemanes, que tras el Ilamamiento que les hizo el Gobierno Vasco en el exilio de apoyar militarmente a Francia, cayeron posteriormente en manos del ejército de ocupación alemán ${ }^{76} . Y$ respecto a

74. "...algunos partidos políticos no han sido reparados en el ámbito de la devolución del patrimonio que les fue incautado. Algunos de los que estamos aquí tuvimos presencia y sufrimos los rigores de la guerra civil, puesto que formamos parte del bando perdedor. Olvido sí y dejar descansar a los muertos sí, pero reparación también, señor Fernández. Reparación es lo que tenemos que hacer consensuadamente entre todos..." Emilio Olabarría Muñoz, en DSCD- 2005-072 24/2/05.

75. "El revisionismo histórico y las construcciones de verdades extrañas son las de aqueIlos que niegan el Holocausto, las de aquellos que hacen libros de elogio y justificación de la época franquista, como hemos asistido en los últimos años, las de aquellos que se escandalizan cuando se quitan las estatuas de dictadores, que es increíble que sigan permaneciendo en este país, y tantos nombres de represores en las calles de este país después de tantos años. Aquellos que se escandalizan por eso son los que hacen revisionismo histórico, aquellos que sitúan al mismo nivel a una dictadura feroz con una democracia como si hubiera sido solo un conflicto de pareceres, aquellos que señalan lo idílico - y luego entraré más en esto- de la concordia de 1978 [...] Con la transición, aquellos que mantuvieron un estatus privilegiado, que tuvieron prebendas, que hicieron negocios, que se aprovecharon del régimen dictatorial, después de esa transición, siguieron con las prebendas, siguieron con el dinero y siguieron con el mismo estatus, mejor todavía, porque lo que se produjo con la transición política es una especie de limpieza de cara a todos y cada uno, sin que eso supusiera asumir cuentas por actuaciones antidemocráticas. Fue un blanqueo político. ¿Es eso lo idílico de la transición?", Aitor Esteban Bravo, en DSCD-172-2006 27/4/06.

76. “...personas de diferentes ideologías — vascos, abertzales, socialistas, anarquistas, comunistas- que tuvieron que abandonar su país tras el triunfo de la sublevación fran- 
la Transición, de nuevo la postura del PNV fue clara, "se ha producido una transición política absolutamente impostada y basada en postulados de una especie de perdón también tan impostado como la propia dimensión de la transición política"177y en la que implicaba también a la monarquía que fue impuesta por Franco ${ }^{78}$.

\section{Conclusiones}

En general se observa un frecuente uso político del pasado del PNV aunque de forma oscilante. Abundante pero contenido durante las dos primeras legislaturas en las que se inició y construyó las bases del autogobierno vasco; casi testimonial en los años de los gobiernos socialistas de Felipe González y primer gobierno de Aznar, -periodos de alianzas con otras formaciones políticas de ámbito estatal- y más acentuado tras el Pacto de Estella de 1998. En estos años finales del siglo emergía con fuerza el recurso del pasado, esta vez como arma política también. Entonces la Transición pasó a ser vista como un periodo de desajustes, donde la construcción de un Estado democrático se hizo con el olvido de una parte del pasado y donde las leyes de amnistía cerraron el paso a las demandas de justicia y reparación a las víctimas de la guerra y la dictadura.

quista y fueron agrupadas, en el caso de los vascos, en el campo de Gurs sobre todo, en el Béarn francés, para después secundar el Ilamamiento del Gobierno de Euskadi en el exilio para apoyar a Francia militarmente o movilizándose en la fortificación de la Línea Maginot. Esos cientos, miles de refugiados republicanos fueron trasladados a la fuerza por los nazis a fábricas de explosivos en Estrasburgo y después fueron internados en Mauthausen, Dachau o Ravensbrück. Esto fue posible también gracias a Madrid, claro que sí, con la colaboración y el consentimiento del Gobierno español, que no es que no diera un paso para impedirlo, sino que dio facilidades para que pudiera suceder", Aitor Esteban Bravo, en DSCD-279-2015 12/5/15.

77. Emilio Olabarria Muñoz, en DSCD-112-2013 21/5/13.

78. "Hace treinta y seis años se realizó el llamado pacto constitucional, que fue refrendado por la ciudadanía en un pack como un conjunto indiscutible. La monarquía, señalada por el dictador como su sucesora, quedaba acomodada, y sobre todo insertada, asentada en los nuevos tiempos a través de aquel pacto, [...] quienes alaban acríticamente el pacto constitucional se olvidan interesadamente de las imposiciones preconstitucionales. Aquel pacto estuvo constreñido por la realidad de un régimen dictatorial cuyas fuerzas vivas controlaban todos los resortes del poder y amenazaban con la regresión y la represión si las aguas llegaban a salirse de su cauce. En aquel acuerdo hubo algunas materias no sujetas a discusión, impuestas; desde el mantenimiento en su puesto de jueces, militares y funcionarios que habían participado en la represión del régimen hasta la propia forma de gobierno, la monarquía", Aitor Esteban Bravo, en DSCD-204-2014 11/6/14. 
Cuadro 2. PNV: Menciones al pasado desglosadas por legislaturas. Fuente: Elaboración propia a partir de los Diarios de Sesiones del Congreso de los Diputados.

\begin{tabular}{|c|c|c|c|c|c|c|c|c|}
\hline LEGISLATURAS & 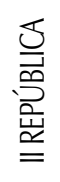 & 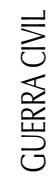 & 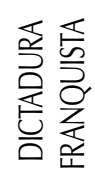 & $\frac{o}{\stackrel{ }{\bar{z}}}$ & 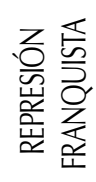 & 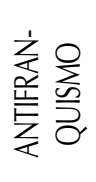 & 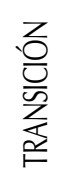 & $\underset{\wp}{\stackrel{\Sigma}{\varrho}}$ \\
\hline CONST. 1977-1979 & 2 & 4 & 3 & 1 & 4 & 1 & 2 & 17 \\
\hline I LEG. 1979-1982 & 4 & 1 & 2 & 2 & 0 & 1 & 0 & 10 \\
\hline II LEG. 1982-1986 & 2 & 0 & 2 & 1 & 0 & 1 & 0 & 6 \\
\hline III LEG. 1986-1989 & 3 & 3 & 3 & 3 & 2 & 3 & 0 & 17 \\
\hline IV LEG. 1989-1993 & 2 & 0 & 0 & 1 & 1 & 1 & 0 & 5 \\
\hline V LEG. 1993-1996 & 3 & 0 & 2 & 0 & 2 & 0 & 0 & 7 \\
\hline VI LEG. 1996-2000 & 5 & 3 & 3 & 1 & 1 & 0 & 1 & 14 \\
\hline VII LEG. 2000-2004 & 10 & 8 & 6 & 0 & 5 & 3 & 10 & 42 \\
\hline VIII LEG. 2004-2008 & 6 & 7 & 7 & 1 & 8 & 1 & 9 & 39 \\
\hline IX LEG. 2008-2011 & 0 & 1 & 1 & 0 & 0 & 0 & 0 & 2 \\
\hline X LEG. 2011-2015 & 0 & 3 & 4 & 1 & 3 & 0 & 3 & 14 \\
\hline TOTAL & 37 & 30 & 33 & 11 & 26 & 11 & 25 & 173 \\
\hline
\end{tabular}

El recuerdo de la Guerra Civil es utilizado por el PNV en los primeros años de la democracia, centrado principalmente en torno a los derechos históricos vascos, al Estatuto y al Concierto Económico recuperados con la República y perdidos durante la Guerra Civil, recuerdo enmarcado en este periodo dirigido a la consecución de mayores cuotas de autogobierno durante los años de construcción del Estado de las Autonomías. Por otra parte, las reiteradas evocaciones a la lealtad del partido hacia el gobierno republicano, iba dirigida a ocultar el apoyo de parte de la militancia al bando nacional durante el conflicto bélico. Más adelante también, haciendo un paralelismo con la Guerra Civil, en torno a las cuestiones legislativas referidas a los conflictos bélicos de estos años: Kosovo, Afganistán o Irak, no así con la guerra del Golfo y de los Balcanes a principios de la década de los noventa -periodo de pactos con los socialistas-y por último, para señalar la represión y destrucción sufrida en Euskadi por parte del ejército nacional.

La evocación a la II República tuvo dos objetivos: uno para recordar su fidelidad y el afianzamiento del carácter incuestionablemente democrático del partido frente a la dictadura franquista, periodo en el que, desde el exilio, practicó una labor de lucha antifranquista con el objetivo único de derribar al régimen, siendo un discurso habitual en relación a la incorporación de España a las instituciones internacionales donde se presenta como un partido de tradición europeísta; y otro para legitimar los pactos con los 
socialistas en el Gobierno Vasco acudiendo al recuerdo de sus alianzas durante la II República.

EI PNV considera el periodo de transición a la democracia como un tiempo en el que las élites franquistas impusieron un modelo de construcción de un nuevo Estado a costa del olvido del pasado, obviando que fue en estos años cuando consiguieron parte de sus aspiraciones nacionalistas y contradiciendo esta imagen negativa de la Transición a la alabanza que de este periodo hacía el PNV de la mano de Arzallus en 1978.

Por último, el PNV ha construido un relato con rasgos victimistas en el que se presenta como un partido que ha tenido que enfrentarse a lo largo de su historia, a posicionamientos tanto progresistas como conservadores para la consecución de sus aspiraciones soberanistas, haciendo frente a las acusaciones de deslealtad con el Estado por aprovechamiento político de las acciones terroristas de ETA y por utilizar los pactos de gobierno con PSOE y PP para la conquista de mayores cuotas de autogobierno, utilizando para ello el recuerdo del pasado reciente de nuestra Historia.

\section{Bibliografía}

AGUILAR FERNÁNDEZ, Paloma: “Aproximaciones teóricas y analíticas al concepto de memoria histórica: la memoria histórica de la guerra civil española (1936-1939)", en Carlos BARROS GUIMERANS (Coord.): Historia a debate: Actas del Congreso Internacional "A historia a debate". Celebrado del 7 al 11 de julio de 1993 en Santiago de Compostela, Vol. 2, Santiago, Ed. Historia a Debate, 1995, pp. 129-142.

AGUILAR FERNÁNDEZ, Paloma: La memoria histórica de la guerra civil española (1936-1939): un proceso de aprendizaje político, Madrid, Centro de Estudios Avanzados en Ciencias Sociales, 1995.

AGUILAR FERNÁNDEZ, Paloma: Memoria y olvido de la Guerra Civil española, Madrid, Alianza Editorial, 1996.

AGUILAR FERNÁNDEZ, Paloma: Políticas de la memoria y memorias de la política, Madrid, Alianza Editorial, 2008.

CRESPO ALCAZAR, Alfredo: "Autonomía vs. Independencia en el PNV durante la transición española", en Carlos NAVAJAS ZUBELDÍA y Diego ITURRIAGA BARCO (Eds.): Coetánea. Actas del III Congreso Internacional de Historia de Nuestro Tiempo, Logroño, Universidad de la Rioja, 2012, pp. 285-290.

ESPINOSA MAESTRE, Francisco: Contra el olvido. Historia y memoria de la guerra civil, Barcelona, Crítica, 2006.

ESPINOSA MAESTRE, Francisco: "De saturaciones y olvidos. Reflexiones en torno a un pasado que no puede pasar", Hispania Nova. Revista de Historia Contemporánea, 7 (2007), pp. 413-440. http://hispanianova.rediris.es [Consultado 6-2-2021] 
FERNÁNDEZ SOLDEVILLA, Gaizka y JIMÉNEZ RAMOS, María (Coords.): 1980. El terrorismo contra la Transición, Madrid, Tecnos, 2020.

FONTANA, Josep: “¿Para qué sirve la memoria histórica?”, Clío, 61 (2006), pp. 16-17.

GONZÁLEZ MARTÍNEZ, Carmen: "Recuperar la memoria y el pasado histórico para comprender el presente de Euskadi", Anales de Historia Contemporánea, 20 (2004), pp. 507-514.

GRANJA SAINZ, José Luis de la: "El error de Estella del PNV en perspectiva histórica", Anales de Historia Contemporánea, 16 (2000), pp. 199-207.

GRANJA SAINZ, José Luis de la: "Luces y sombras en la historia del Partido Nacionalista Vasco. Comentarios sobre el péndulo Patriótico", Pasado y Memoria. Revista de Historia Contemporánea, 1 (2002), pp. 5-26.

GRANJA SAINZ, José Luis de la: El nacionalismo vasco: un siglo de historia, Madrid, Tecnos, 2002.

GRANJA SAINZ, José Luis de la: El siglo de Euskadi. El nacionalismo vasco en la España del siglo XX, Madrid, Tecnos, 2003.

JULIÁ, Santos: "Echar al olvido. Memoria y amnistía en la transición", Claves de Razón Práctica, 129 (2003), pp. 14-25.

JULIÁ, Santos (Coord.): Memoria de la guerra y del franquismo, Madrid, Taurus, 2006.

LANDABEREA ABAD, Eider: Los "nosotros" en la Transición: memoria e identidad en las cuatro principales culturas políticas del País Vasco (1975-1980), Madrid, Tecnos, 2016.

LLERA RAMO, Francisco José: "Pluralismo y gobernabilidad en Euskadi, 19801994", WP Institut de Ciències Polítiques i Socials, 162 (1999), pp. 1-33.

MATEOS LÓPEZ, Abdón: "La construcción de una conciencia histórica democrática y los medios de comunicación durante la «Transición». Notas para su estudio", en Rafael QUIROSA-CHEYROUZE Y MUÑOZ (ed.): Prensa y Democracia. Los medios de comunicación en la Transición, Madrid, Biblioteca Nueva, 2009, pp. 77-86.

MATEOS LÓPEZ, Abdón: Historia del antifranquismo, Barcelona, Ed. Flor del viento, 2011.

MONTERO GARCÍA, Manuel: "La historia y el nacionalismo. La visión del pasado en el partido nacionalista vasco, 1976-2005", Historia Contemporánea, 30 (2005), pp. 247-276.

MONTERO GARCÍA, Manuel: "El nacionalismo moderado durante la Transición. La conquista de la hegemonía en el País Vasco", Cuadernos de Historia Contemporánea, 36 (2014), pp. 331-351.

MONTERO GARCÍA, Manuel: "La presión terrorista durante la Transición y la formación nacionalista de la autonomía vasca", Historia Actual Online, 55 (2021), pp. 23-36. 
MUÑOZ BOLAÑOS, Roberto: Guernica. Una nueva historia, Barcelona, Espasa, 2017.

MUÑOZ BOLAÑOS, Roberto: "El nuevo Estado democrático frente al desafío terrorista", en Gaizka FERNÁNDEZ SOLDEVILLA y María JIMÉNEZ RAMOS (Coords.): 1980. El terrorismo contra la Transición, Madrid, Tecnos, 2020, pp. 227-253.

PABLO, Santiago de: "El nacionalismo vasco ante el estado español (18951937)", Studia historica. Historia contemporánea, 18 (2000), pp. 79-93.

PABLO, Santiago de y MEES, Ludger: El péndulo patriótico. Historia del Partido Nacionalista Vasco (1895-2005), Barcelona, Crítica, 2005.

PÉREZ CALVO, Alberto: "El plan Ibarretxe y su grave déficit democrático de partida", Revista de Estudios Políticos (Nueva Época), 126 (2004), pp. 9-28.

REIG TAPIA, Alberto: La cruzada de 1936. Mito y memoria, Madrid, Alianza Editorial, 2006.

RUIZTORRES, Pedro: "Los historiadores y los usos públicos del pasado reciente en España", I'Atelier international des usages publics, marzo (2011). http:// usagespublicsdupasse.ehess.fr/ [Consultado 11/01/2021]

VÍRGALA FORURIA, Eduardo: "La reforma territorial en Euskadi: los Planes Ibarretxe I (2003) y II (2007)", Cuadernos Constitucionales de la Cátedra Fadrique Furió Ceriol, 54/55 (2006), pp. 159-187. 